\title{
CHALLENGES FACED BY THE ADOPTION OF BIG DATA IN THE DOMINICAN REPUBLIC CONSTRUCTION INDUSTRY: AN EMPIRICAL STUDY
}

\author{
SUBMITTED: September 2021 \\ REVISED: October 2021 \\ PUBLISHED: November 2021 \\ GUEST EDITORS: Nashwan Dawood, Farzad Pour Rahimian \\ DOI: $10.36680 /$ j.itcon. 2021.044
}

Paola F. Reyes-Veras, MSc.

Faculty of Science and Engineering, University of Wolverhampton, Wolverhampton, United Kingdom p.reyesveras@wlv.ac.uk

\author{
Suresh Renukappa, PhD \\ Faculty of Science and Engineering, University of Wolverhampton, Wolverhampton, United Kingdom \\ Suresh.renukappa@wlv.ac.uk \\ Subashini Suresh, PhD \\ Faculty of Science and Engineering, University of Wolverhampton, Wolverhampton, United Kingdom \\ s.subashini@wlv.ac.uk
}

SUMMARY: The adoption of Big Data (BD) in the construction industry has been identified as a possible solution to the demand of the current needs of projects, but the integration of this technology has proven to be a challenge specially in industries such as construction that are not technological driven. The understanding of the key elements for the BD adoption has become the focus of many industries that seek to exploit the benefits offered by this technology. Therefore, this paper aims to explore the challenges faced by the adoption of BD in the Dominican Republic (DR) construction industry. To identify these challenges qualitative research was undertaken due to the paucity of scientific data. Twenty-one individuals representing 19 companies who have great impact in the DR construction sector were interviewed. From the analysis six main challenges were identified. They are: lack BD awareness, high cost of investment, resistance to change, lack of government support and regulation, lack of technological expertise, and security concerns of BD. The challenges identified in this study, will serve to help companies better plan their technology adoption process, mainly considering aspects such as the need to tackle the lack of awareness by disseminating and promoting the concept of BD which will not only generate a better understanding of technology by making sure that present and future professionals understand the technology and its benefits. This study provides insight in the challenges to overcome for a successful adoption of BD technology, which would help companies to prepare for a future adoption.

KEYWORDS: Awareness, Big Data, resistance to change, security

REFERENCE: Paola F. Reyes-Veras, Suresh Renukappa, Subashini Suresh (2021). Challenges faced by the adoption of big data in the Dominican Republic construction industry: an empirical study. Journal of Information Technology in Construction (ITcon), Special issue: 'Construction 4.0: Established and Emerging Digital Technologies within the Construction Industry (ConVR 2020)', Vol. 26, pg. 812-831, DOI: 10.36680/j.itcon.2021.044

COPYRIGHT: () 2021 The author(s). This is an open access article distributed under the terms of the Creative Commons Attribution 4.0 International (https://creativecommons.org/licenses/by/4.0/), which permits unrestricted use, distribution, and reproduction in any medium, provided the original work is properly cited. 


\section{INTRODUCTION}

There are industries that are characterized by staying at the forefront of new technologies, and others that are characterized by the opposite, the construction industry belongs to the latter (Silverio Fernandez et. al., 2020), construction methods and materials have evolved little or nothing in the last decades, contrary to the needs of the society and the environment, which require that projects increasingly provide experiences more tailored to the needs of users while adequately managing resources in all stages of development (CLC, 2021). This resistance to change, common aspect for the construction industry, has been challenged in recent years by the development of new technologies that seek to improve the way construction projects are delivered. Tools such as Building information modelling (BIM), Big Data, smart cities and devices and so on, are characterized by improving the management of resources as well as decision-making in the projects (Bello, 2021). Solutions such as problemsolving throughout the different stages of a project in the case of BIM (Nik-Bakht et. al., 2021), and the efficient allocation of resources and life independence as a result of Smart Cities implementations (Naoui et. al., 2021), are only some of the benefits that these technologies bring to the industry have made their adoption considered a necessity nowadays.

Big Data Analysis is a tool that has positively impacted every industry who has adopted it as part of their product or service delivery processes, for instance, in both previous cases of technological development (BIM and implementation of smart cities), BD plays a major role in the optimization of these tools through the management of the large volumes of data that they generate and need to analyse (Sayah et. al., 2021). Nevertheless, the integration of the technology is not always been successful and depends generally on the industry's ability to handle and integrate new technologies or, in other words, it depends on whether or not the industry is technology driven (Silverio Fernandez et. al., 2019). Sources such as Vellante, (2021), identifies BD as a key technology for the construction industry in the future. This is because of its applications in resource management, project life cycle and decision making which makes this technology a key element so that construction industry can keep up to date with the demands of today's society. But due to its adherence to traditional practices, the adoption of BD is an uphill task which generates the need to provide the industry with the necessary tools to understand and assimilate the benefits of BD as well as the key elements to achieve its adoption.

Therefore, the aim of this study is to explore the specific challenges faced by the adoption of new technologies such as BD in the construction industry. Due to the scarce information on the issue of BD technology adoption, a qualitative research method was implemented, where the necessary data was collected through semi-structured interviews to identify the challenges faced by the adoption. These interviews were carried out within the framework of the construction industry of the Dominican Republic, which has characteristics that favours the realization of a study of this type through investment in technologies such as BIM and Drones (Silverio Rodriguez, 2020; and Silverio Fernandez, 2019), thus providing an insight into the aspects that need to be addressed to successfully adopt the technology as part of a construction company and soon the industry. For this, a theoretical background will be presented to introduce and discuss the elements involved in the research such as Big Data, Construction, Challenges for adoption of new technologies and the selection of the Dominican Republic as a base for the study, then the methodology used to develop the study will be presented, followed by the data analysis. Finally, the results will be presented and discussed in the subsequent sections followed by the conclusion and recommendations.

\section{BACKGROUND}

Data analysis is a process through which insights are extracted from a cluster of structured data, when the characteristics of this datasets exceeds the capability of traditional analysis tools, the analysis process is known as Big Data (BD) or Big Data Analysis (BDA) (Miloslavskaya \& Tolstoy, 2016). BD is already a well-known technology in some industries that rely on digital data to carry out their operations such as telecommunications, healthcare, and finance (Tabesh, et. al., 2019 and Chen et. al., 2020), and a fairly new concept for others that are not so much technologically driven such as manufacturing and construction (Silverio-Fernandez et. al., 2019; and Chang et. al., 2021). This technology which promises to improve the decision-making process of companies as well as their resource management capabilities has become a key tool for business development in recent years. Figure 1, presents the main elements of BD. 


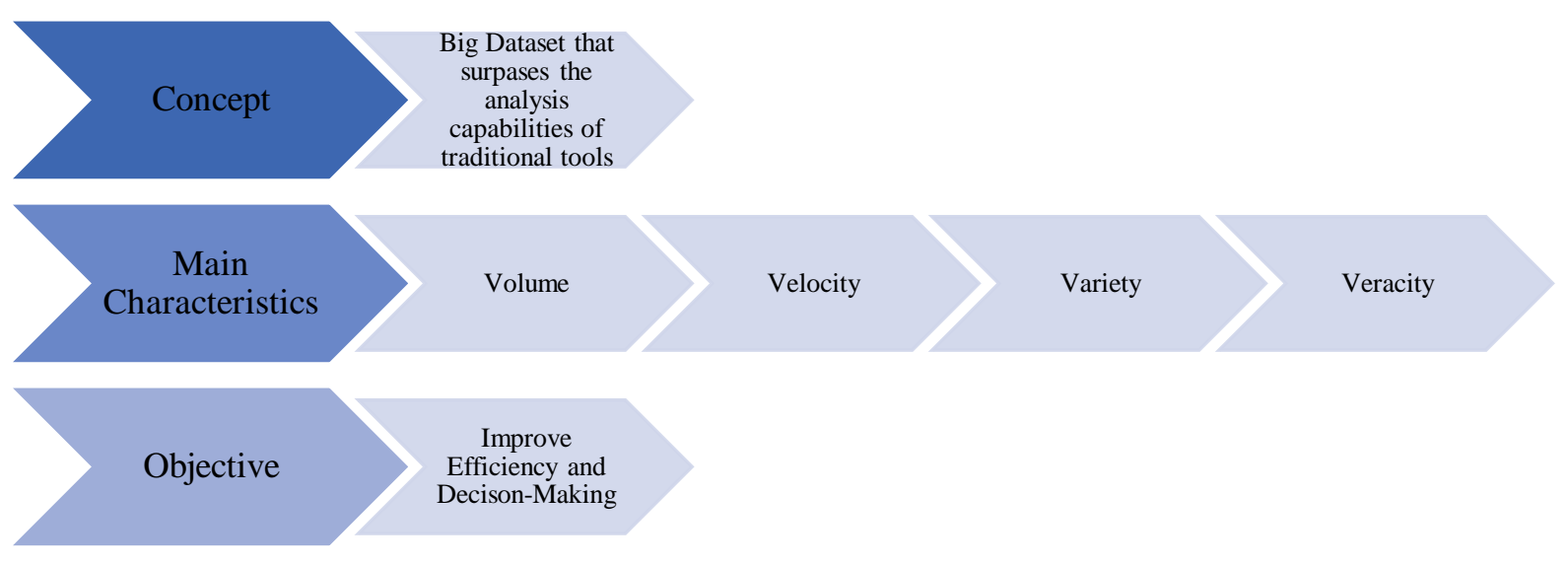

\section{Figure 1: Essential elements of Big Data}

BD technology has been implemented for years in some industries such as retail, healthcare, and banking (Aversa et. al., 2021; Chen et al., 2020; Salleh and Janczewski, 2019; and Wu et. al., 2017), even so, studies exploring its adoption are scarce and do not include the exploration of adoption in less data-driven industries such as construction. The following table (Table 1), which is a compilation of the sources of Mourtzis et. al., (2016); Wu et. a., (2017); Raguseo, (2018); Caesarius and Hohental, (2018); Silva et. al., (2019); Salleh and Janczewski, (2019); Baig et. al., (2019); Knowles, (2020); Balti et. al., (2020); Bag et. al., (2021); and Aversa et. al., (2021), and it presents some examples of similar research where the adoption of BD is explored.

Table 1: Big Data Adoption Studies

\begin{tabular}{|c|c|c|c|}
\hline Title & Year & Industry & Country / Region \\
\hline Industrial Big Data as a Result of IoT Adoption in Manufacturing. & 2016 & Manufacturing & Greece \\
\hline $\begin{array}{l}\text { Adoption of big data and analytics in mobile healthcare market: An economic } \\
\text { perspective. }\end{array}$ & 2017 & Healthcare & USA \\
\hline $\begin{array}{l}\text { Searching for big data: How incumbents explore a possible adoption of big data } \\
\text { technologies. }\end{array}$ & 2018 & Various & Scandinavia \\
\hline Big Data Application for Selecting Theses Topics. & 2019 & Higher Education & India \\
\hline Big data adoption: State of the art and research challenges. & 2019 & Various & Malaysia \\
\hline $\begin{array}{l}\text { Security Considerations in Big Data Solutions Adoption: Lessons from a Case } \\
\text { Study on a Banking Institution. }\end{array}$ & 2019 & Banking & Malaysia \\
\hline $\begin{array}{l}\text { Role of institutional pressures and resources in the adoption of big data analytics } \\
\text { powered artificial intelligence, sustainable manufacturing practices and circular } \\
\text { economy capabilities. }\end{array}$ & 2020 & Manufacturing & South Africa \\
\hline $\begin{array}{l}\text { Big data analytics adoption: Determinants and performances among small to } \\
\text { medium-sized enterprises. }\end{array}$ & 2020 & $\begin{array}{l}\text { Business } \\
\text { Manufacturing }\end{array}$ & Iran \\
\hline Big data management in healthcare: Adoption challenges and implications. & 2020 & Healthcare & Taiwan \\
\hline $\begin{array}{l}\text { Strengths and Limitations of Harnessing Big Data to Understand the Genetics of } \\
\text { Adoption and Mental Health. }\end{array}$ & 2020 & $\begin{array}{l}\text { Mental Health / } \\
\text { healthcare }\end{array}$ & USA \\
\hline Incorporating big data within retail organizations: A case study approach. & 2021 & Retail & Canada \\
\hline
\end{tabular}




\subsection{The construction industry and its need for modernization}

The construction industry plays a major role in the evolution of society, by supporting the development of the built environment, it also became one of the main characters in resources consumption, waste creation and $\mathrm{CO} 2$ emissions produced (Willar et. al., 2021). Today's society demands that these activities are performed with a sustainable approach, these new requirements, which affect both existing and new projects, are forcing the industry to modernize and adopt technologies that allow a more conscientious management of resources as well as the improvement of efficiency in the project delivery processes (CLC, 2018).

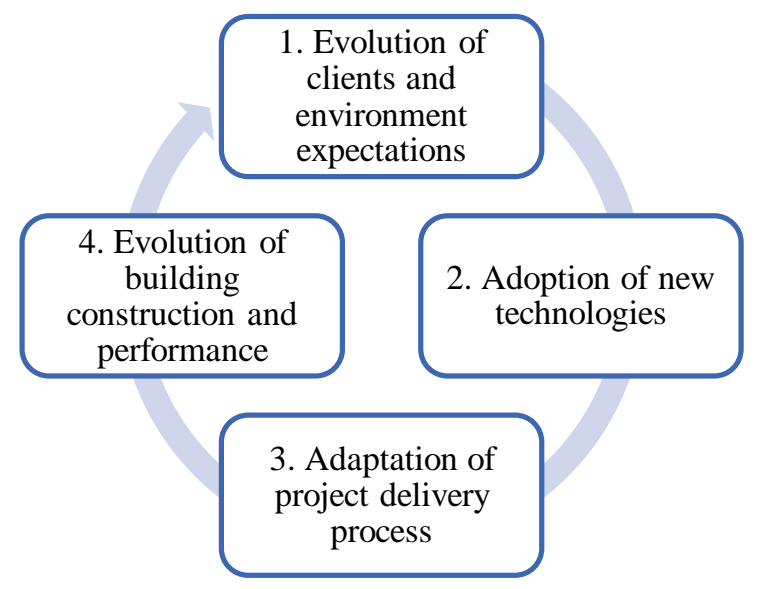

Figure 2: Industry innovation cycle

Source: Adapted from "Innovation in construction life cycle", Abusalah, 2021.

Nowadays, construction projects are required to include smart designs and features that are consistent with the technological and sustainable needs of users and environment (Oudjehane and Moeni, 2017; and CLC, 2021), which has forced companies to adopt technologies that allow them to deliver projects that meet these expectations by improving not only the way the projects are constructed but also improving the way buildings and infrastructures perform once they are finished (Vellante, 2021; and Abusalah, 2021). Thus, creating an evolving cycle (Fig. 2) that forces industries to keep innovating and at the same time to keep up with society's technological development (Abusalah, 2021). Also, the industry's lack of innovation has produced a reduction in the productivity, which reinforces the need for digitization (Jahanger et. al., 2021). Moreover, Chalhoub et. al., 2021 goes further, stating that the use of technology in the industry could alleviate the shortage of personnel by using tools such as AR so untrained workers can perform specific task allowing experienced professionals to focus on more demanding assignments.

$\mathrm{BD}$ has been identified, as a solution to the need of modernization of industries like construction, since the benefits of this technology are aligned with the needs of the industry such as managing the increasing data volumes (Body \& Crawford, 2012; Caesarius and Hohental, 2018; and Cheng et. al., 2020), transparency requirements (Kurshid et. al., 2019) and waste generation (Lu, 2019; Xu et. al., 2020; and Lu et al., 2021) to mention a few, while at the same time, the industry is increasingly able to meet the requirements of the technology through the generation and storage of diverse digital datasets, digitalization of projects and processes and inclusion of data generating and transmitting smart devices such as real-time location sensors (Johansen et. al., 2021), throughout project lifecycle of construction, operation to the end of its useful life and potential reuse, recycling, or demolishing (Oudjehane and Moeni, 2017).

Wang et. al., (2019), explains that the successful adoption of technology depends on a series of unique factors and characteristics, even so, when the attributes and characteristics of Big Data (BD) are well defined elements for some industries where its successful adoption and benefits have been recorded and studied for years, not all companies manage to adopt the technology despite making large investments, and nevertheless, there is very little information on the challenges that a company must overcome to successfully adopt $\mathrm{BD}$, then much less information in industries like construction with much lower levels of adoption or where the technology is just beginning to be recognised. 


\subsection{Challenges for adopting new technologies such as BD within construction}

In order to close the gap between a technology promise and its achievement some challenges must be overcome (Leonard-Barton and Kraws, 1985). Each change that is implemented regardless of whether it is at company or industrial level brings its own challenges, and in this case, the implementation of $\mathrm{BD}$ in construction companies and industry is not an exception (Baig et. al., 2019; and Small, 2019). So far, the challenges experienced by industries with more experience in BD adoption are presented in two ways: industrial challenges and organizational challenges, the former referring to general problems that industries face when adopting BD and the later referring to specific issues faced by the organizations. The bullets points were compiled based on the analysis of the sources of TatvaSoft, (2021); Chuah et. al., (2021); Gohil and Akhilesh, (2018); Shah et. al., (2017); and Balti et. al., (2020).

\subsubsection{Industrial challenges}

- Data privacy, governance, and compliance issues: question raised around the source of data and how it is used.

- Defining what BD is and how it can help businesses: the lack of homogeneous concept makes the understanding of technology difficult.

- Integrating legacy systems with BD technology: how to avoid the loss of data when upgrading or transferring to a new system.

- $\quad$ Lack of BD skills: skilled BD analytics workers are hard to find due to skill shortage

- Cost of BD tools: the cost of infrastructure needed to support the capturing of big volumes of data is too high.

- Complex technological requirements: the complexity of infrastructure makes it difficult to obtain.

\subsubsection{Organisational challenges}

- Managerial challenges: organizations fail to treat BD as a continuous exploration project and instead approach it as a time-limited project.

- Economic challenges: most companies face lack of budget, time, and resources necessary to implement BD.

- Data challenges: the incompatibility with the BD characteristics of volume, velocity, variety, and veracity.

- Data processing challenges: any difficulties that arise as part of the gathering, pre-process, or process stage as well as the selection of the analysis tool.

- Infrastructure management challenges: the infrastructure management challenges which refers to the problems generated from the selection and cost of the instruments to perform the analysis.

While most of the challenges presented above are generated across different industries, they are generally identified in data driven activities such as banking and retail (Salleh et. al., 2019; and Aversa et. al., 2021). Challenges such as security concerns and data processing challenges (Bell et al., 2021; and Brandín and Abrishami, 2021), demonstrate a deep understanding of the technology while also showcasing situations in which they would be faced when already trying to adopt the technology, such as lack of skilled personal and knowledge of complexity of technology requirements.

In the case of the other industries like construction, are less technological inclined, there are very few records of the challenges to overcome for the adoption of $\mathrm{BD}$, in the specific case of the construction industry, however, some parallels can be established with the adoption of technologies similar to BD, such is the case of Cloud Computing (Bello et. al., 2021), technology that has digitization requirements similar to BD and whose implementation would facilitate a future adoption of the technology in the industry. Challenges that still today prevent the industry wide adoption of this technology are presented next.

\subsubsection{Cloud computing in construction}

Bello et. al., (2021) work has identified challenges in cloud computing in construction. They are:

- Latency: there is no guaranty of reliable transfer rate and response time in time sensitive applications.

- Trust, data privacy and security: the lack of clarity regarding security perimeter as well as the reluctancy to share private and commercial information. 
- Data availability: inability to access data due to down time from the cloud provider, which could affect the development of the project.

- Data governance: lack of clarity when determining data ownership as well as the requirement for data exchange between all stakeholders.

- Poor broadband connectivity of construction sites: the service relies on uninterrupted availability of internet on site.

- Cost implication of long-term use: the overall cost of the cloud infrastructure over time could exceed the expectations of the users.

- High chances for scoring dark data: large volumes of storage space wasted on data generated by sensors with no meaningful insight.

- Threats of edge computing and other associated technologies: benefits of edge computing overpowering the benefits of centralised cloud computing, thus deeming the technology obsolete.

When analysing the similarities between the challenges faced by the adoption of cloud computing in the construction industry and the challenges faced by the adoption of BD in other industries, it could be established that the common challenges between the two could present themselves during the adoption of BD in the construction industry, even without specific studies detailing its occurrence.

Figure 3 illustrates the challenges that could arise during the adoption of BD in the construction industry. These challenges reflect basic elements on the implementation of the technology that can affect its adoption but there is no work done in the context of DR construction industry.

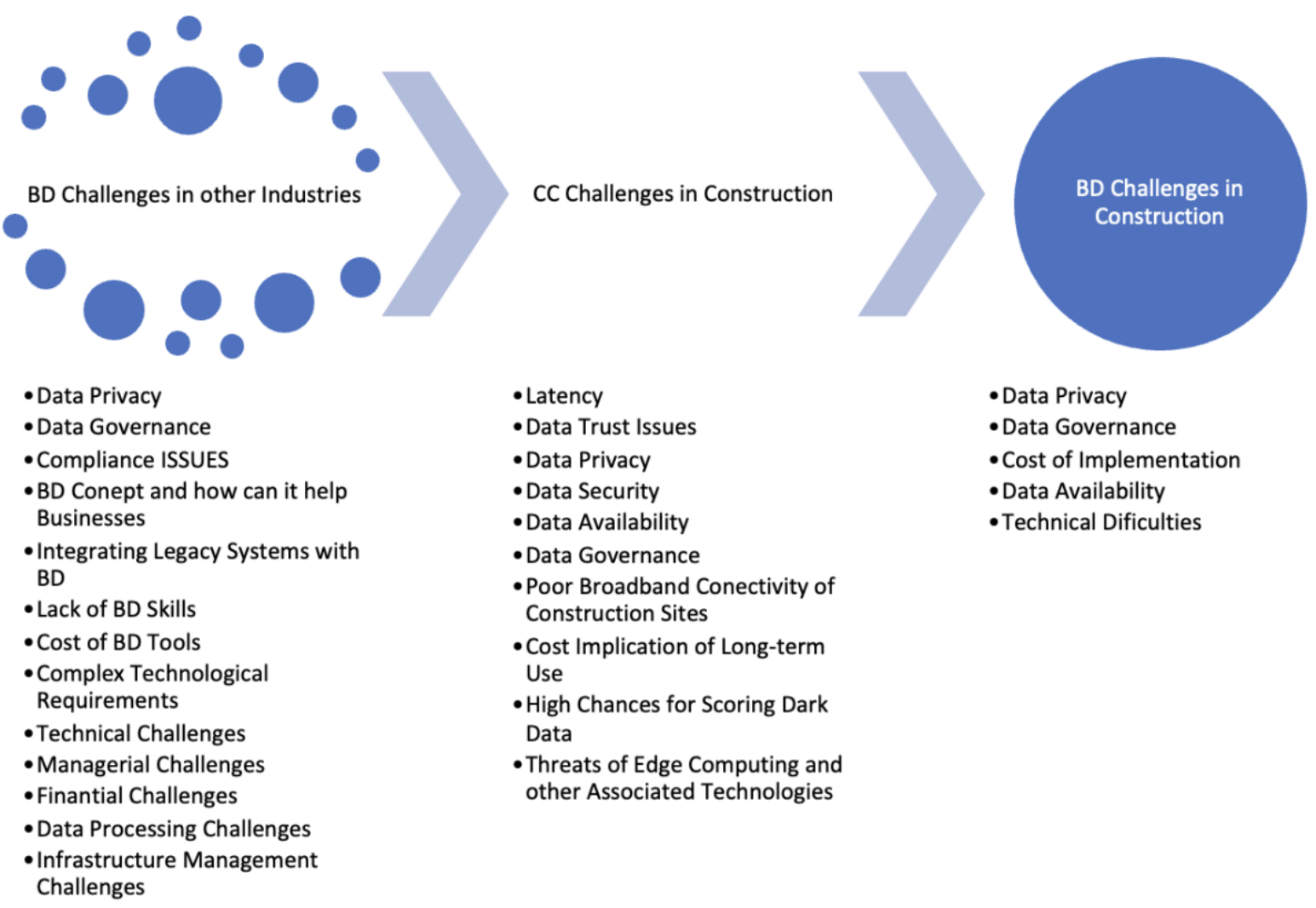

Figure 3: Challenges that the adoption of BD could face in the construction industry

Sources: TatvaSoft, 2021; Chuah et. al., 2021; Gohil and Akhilesh, 2018; Shah et. al., 2017; Balti et. al., (2020); and Bello et. al., 2021. 


\subsection{The Dominican Republic as a case study}

The selection of the Dominican Republic as the data source for this research is based on the importance of the construction industry in the socio-economic environment of the country, where it is considered one of the main economic activities (Valdez Albizu, 2021). Also, the country's economy is considered one of the most important in the region, presenting a stable rate of economic growth for more than a decade (The World Bank, 2021).

Even during the COVID-19 pandemic, the GDP of the Dominican Republic reported an increase of $10.6 \%$ in the period March 2020 - March 2021, of which the construction sector contributed 56.8\% (6.4 points) of this value (Valdez Albizu, 2021). Moreover, there are studies that evidence the use of BIM technology (Silverio Rodriguez, 2020) and the use of smart devices (Silverio-Fernandez et. al., 2019), denoting that there is a significant volume of data generation, which according to (Tamiminia et. al., 2020) is one of the main reasons why technology emerged.

\subsection{Scope of the research and gap}

BD technology has been identified as a possible solution to the pressing needs of modernization to which the construction industry is subjected, its contribution in the areas of improvement of decision making and resource management make this technology a unique tool for the modernization of the industry (Reyes Veras et. al., 2021; and Vellante, 2021). However, in order to achieve this objective an industry-wide adoption is required, and since the construction industry is not the most efficient in adopting new practices and technologies, a deep understanding of the technology, its characteristics and the elements that enable its adoption are needed (Silverio-Fernandez et. al., 2019) Therefore, the objective of this paper is to explore and understand one of the main elements for the adoption of new technologies such as BD which are the challenges that could arise when implementing the technology in the construction industry of the Dominican Republic, so it can be considered beforehand thus avoiding any possible failure influenced by these factors. This study is part of a larger investigation that seeks to explore, understand, and provide guidelines for a future adoption of BD in the industry.

The implementation of BD in construction has become a focal point of studies in recent years (Mourtzis et. al., (2016); Wu et. a., (2017); Raguseo, (2018); Caesarius and Hohental, (2018); Silva et. al., (2019); Salleh and Janczewski, (2019); Baig et. al., (2019); Knowles, (2020); Balti et. al., (2020); Bag et. al., (2021); and Aversa et. al., (2021), despite this, a method of implementation of the technology within the industry has not been documented, in particular, no studies have been found on the elements, like the challenges, would enable the adoption at both organizational and industrial level (Table 1). Hence, the method used in the previous section to present the possible challenges, where similarities were identified between the challenges present in the implementation of BD in other industries and the implementation of cloud technology in construction. These challenges will serve as a point of comparison for the primary data collected in this investigation.

By identifying the challenges faced by implementation of technologies such as BD within the construction industry this paper provides some leverage into aspects that need to be considered for a successful implementation of the technology at both organizational and industrial levels.

This study has been carried out within the domain of the construction industry of the Dominican Republic, since it has the determining characteristics of not having implemented the technology yet but has also generated the conditions for its adoption as the exponential generation of digital data and the willingness to invest in new tools such as BIM and smart devices.

\section{METHODOLOGY}

This segment explains the methodology used to carry out this research, breaking down each step followed to conclude in the results that will be presented in the next section. The process of definition of the methodology began with the selection of the qualitative method of investigation, this due to scarce number of sources exploring the relationship between BD and the construction industry as well as the lack of sources addressing the process of adoption of this technology within the industry (Creswell, 2017), a fact that has been debated in previous sections, this phenomenon is better known as the principle of data availability (Kumar, 2014). The selected method allowed an in-depth exploration of a topic that could not be studied using a quantitative approach (Busetto et. al., 2020).

The data collection process consisted in performing 21 semi-structured interviews in Santo Domingo, Dominican Republic between October 2019, and March 2020. The interviews were directed to representatives of 19 medium 
to large companies that are at the forefront of the market in the country's industry, the representatives in turn, are part of the decision-making team within the companies, which guarantees that they possess not only the knowledge of the protocols necessary for the adoption of a new technology but also, the capability to drive BD adoption in the future. The following figure (Fig. 4) showcases the research design journey for identifying the challenges faced by the adoption of BD in the construction industry of the DR.

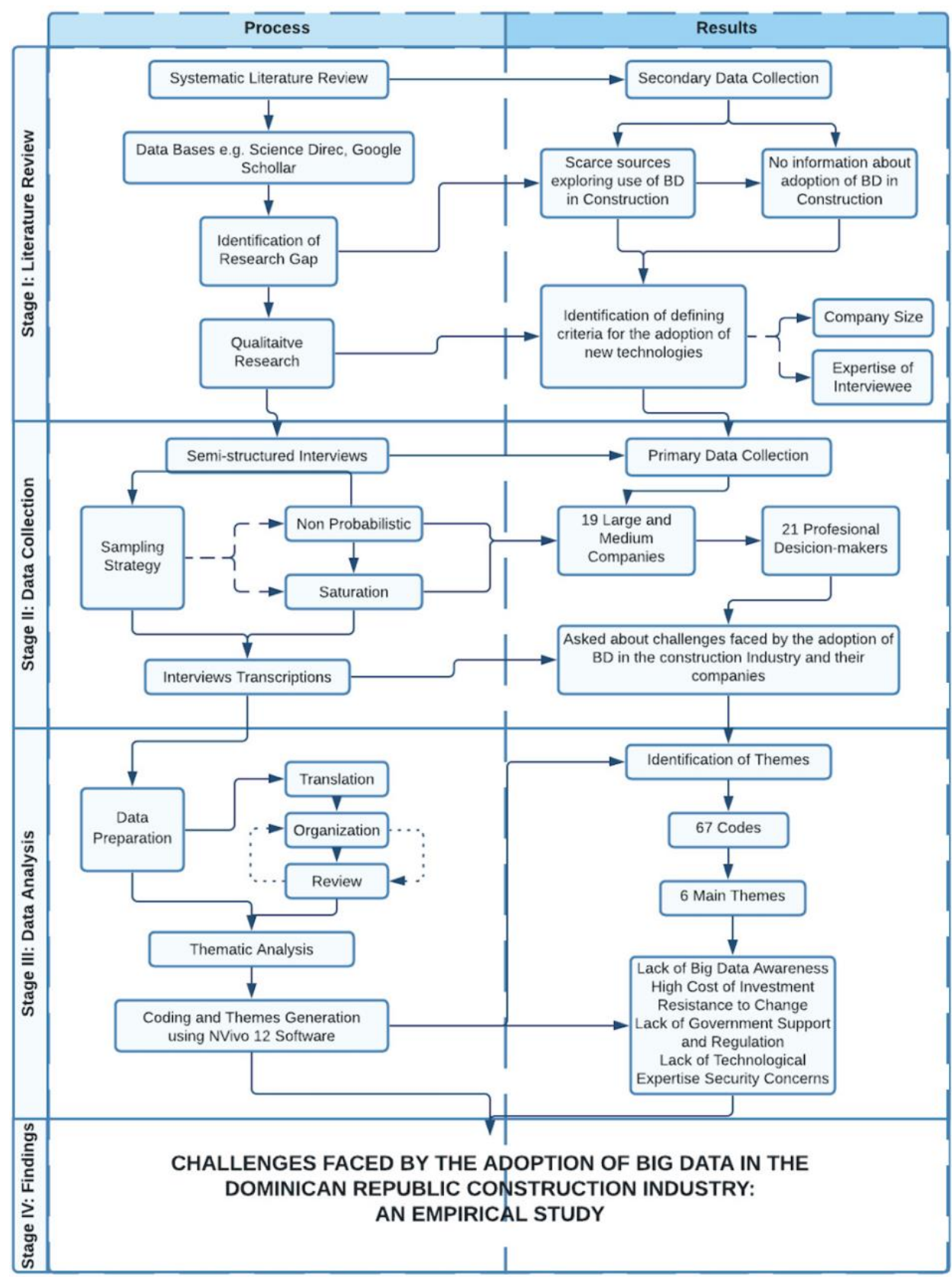

Figure 4: Research Design

\subsection{Design of the interviews}

The design of the interviews was based on the need of assessing the level of BD knowledge possessed by the interviewees and subsequently exploring the factors that would determine the implementation. In this case, this paper presents the results obtained in the search for challenges that would arise when implementing BD technology both at the organizational level and at the industry level. The selection of semi-structured interviews as a data collection method was based on the need to obtain consistent and comprehensive data that would allow the subject 
to be explored in depth (Cohen and Crabtree, 2006). Also, this method is characterized because it allows to capture the point of view of the participants, thus obtaining relevant data that fits the explorative nature of the investigation (DeJonckheere and Vaughn 2019).

In the specific section of the research that is addressed in this paper the interviewees were asked to identify the challenges faced both by their organization and the industry in the adoption of new technologies such as BD as a way to determine if there is a difference between the challenges faced by organizations and those faced by the industry.

\subsection{Selection of sample and data collection}

During the preliminary analysis of secondary data about BD, two factors were established and served to shape the type of sample selected for the data collection, this discovery determined that the method for sample collection is non-probabilistic, which is characterized by using some criteria to select the sample (McCombes, 2019). First, the literature showed that the size of the company influences its ability to invest in new technologies (Ngo, et. al., 2020 and Maroufkhani et. al, 2020), and second, it was also established that people involved in the decisionmaking process of a company not only have a deep knowledge of elements such as drivers, benefits and challenges that can enable the adoption of new technologies but are also in the position of promoting a future adoption.

The company size factors narrowed the sample to large and medium companies, while for the position within the company of the representatives, the selected characteristic was that the interviewees should possess a position that allows them to make decisions about the future of the company.

To identify the companies to whom the invitation to participate in the study would be directed, the official method of company classification of the Dominican Republic was engaged, which is found in the "General Law of Commercial Companies and Individual Limited Liability Companies" (Congreso Nacional de la Republica Dominicana, 2008). This system classifies the companies according to their size and other characteristics, into four lines presented in the following figure (Fig. 5).

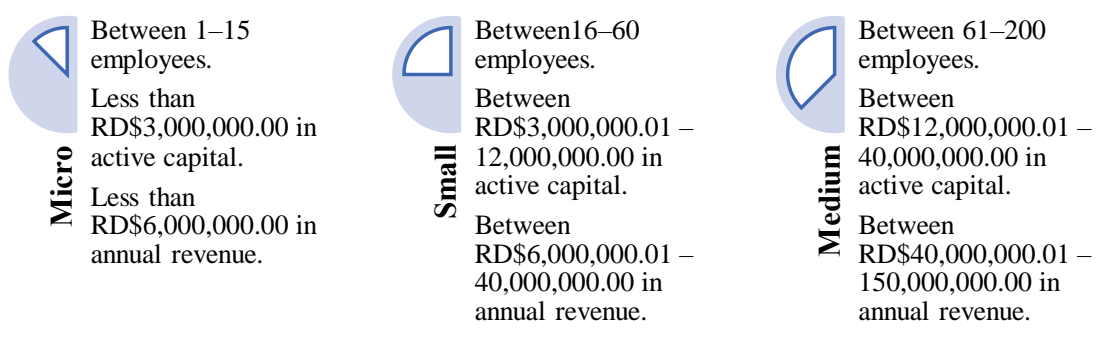

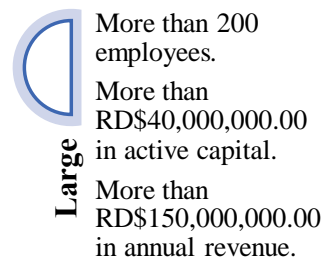

Figure 5: Company classification in the Dominican Republic.

Source: Law 488-08 (National Congress of the Dominican Republic, 2008).

In the same way, the participants were selected according to their position within the participating company, requesting the participation of candidates within the managerial level of the company and who will be part of the decision-making process and, as far as possible, were involved in the development of new technologies within the company. Their demographic information is presented in the Table 2.

Finally, to determine the size of the sample or how many interviews were to be performed, the saturation method was employed. This phenomenon indicates that the number of interviews is enough when new information is no longer produced, that is, no new topic is covered, and the responses provided by the new interviewees are the same or very similar to those of the previous interviewees (Hitchings and Latham, 2020). Studies show that, for the data collection method (semi-structured interviews) used in this study, this phenomenon is usually reached between 15 and 20 interviews (Crouch and McKenzie, 2006). 
Table 2: Demographic information of interviewees

\begin{tabular}{|c|c|c|c|}
\hline Participant & Profession & Position & Company Size \\
\hline 1 & Civil Engineer & BIM Coordinator & Medium \\
\hline 2 & Architect & BIM Manager & Medium \\
\hline 3 & Civil Engineer & Project Manager & Large \\
\hline 4 & Architect & Construction Superintendent & Large \\
\hline 5 & Civil Engineer & Senior Planning and Control Engineer & Medium \\
\hline 6 & Civil Engineer & Engineering and Projects Coordinator & Medium \\
\hline 7 & Civil Engineer & Logistics and Material Supply Manager & Medium \\
\hline 8 & Civil Engineer & Chief Executive Officer (CEO) & Large \\
\hline 9 & Civil Engineer & BIM Construction and Management Manager & Medium \\
\hline 10 & Civil Engineer & Senior Project Planning Engineer & Large \\
\hline 11 & Civil Engineer & Senior Project Cost Controller & Large \\
\hline 12 & Civil Engineer & Project Quality Manager & Medium \\
\hline 13 & Architect & Senior Project Designer & Medium \\
\hline 14 & Civil Engineer & Vice-President of Operations & Large \\
\hline 15 & Civil Engineer & Senior Project Manager & Large \\
\hline 16 & Civil Engineer & Planification and Control Manager & Medium \\
\hline 17 & Civil Engineer & Senior Project Manager & Large \\
\hline 18 & Civil Engineer & Project Superintendent & Medium \\
\hline 19 & Civil Engineer & Senior Project Manager & Medium \\
\hline 20 & Civil Engineer & Engineering and Projects Coordinator & Medium \\
\hline 21 & Civil Engineer & Senior Project Manager & Medium \\
\hline
\end{tabular}

Based on the above, the interview process culminated in interview number 21. Moreover, this process took place between October 2019 and March 2020 in the Dominican Republic, the interview capture method employed was voice recordings which lasted between nine (9) and twenty-two (22) minutes approximately.

\subsection{Data Analysis}

To extract information from the collected data a thematic analysis was carried out. First, the preparation process consisted in the partial application of Creswell's process for preparing interviews for analysis, the adopted stages consisted in the transcriptions of the audio interviews, followed by the preparation and iterative review of transcripts (Creswell, 2013). Then, another step was required, regarding the translation of the interviews from the Spanish, original language in which they were carried out in the Dominican Republic, to English, which is the language in which the analysis and the rest of the research was performed, to finally proceed with the main analysis process.

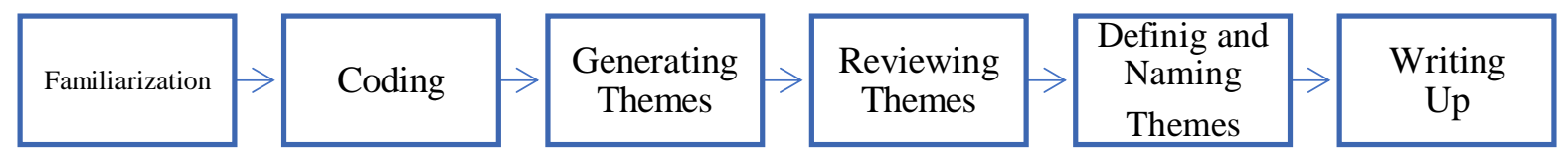

Figure 6: Thematic analysis process.

Source: Adapted from Braun et. al., (2019) 
This method, which establishes that through a systematic six-step process, common ideas, patterns, and themes can be identified among the analysed data (Caufield, 2019), is particularly effective for the analysis of interview transcripts. The six steps or stages of the analysis process presented in the Figure 6 , are done iteratively until generating the main topics that include all the information contained in the data (Braun et. al., 2019). To streamline the process of generating codes and themes, this study employed NVivo software, which according to McNiff (2016), is a tool specially designed for the analysis of qualitative research.

Lastly, the objective of the analysis is reached when an understanding of the information contained in the data is produced by reviewing the relationship between the codes and the interviews (Martinez, et. al., 2021), in this case, the identification of challenges that technologies such as BD face when being adopted in construction both at an organizational and industrial level.

\section{CHALLENGES FOR ADOPTION OF BIG DATA CONCEPT IN THE CONSTRUCTION INDUSTRY}

In this section the challenges faced by the adoption of the BD concept in the construction industry will be presented and discussed. The identification of these challenges enables the industry to prepare ahead and when possible, avoid them altogether. Figure 7 introduces the issues faced by companies and the industry that have been identified by the interviewees during the data collection process.

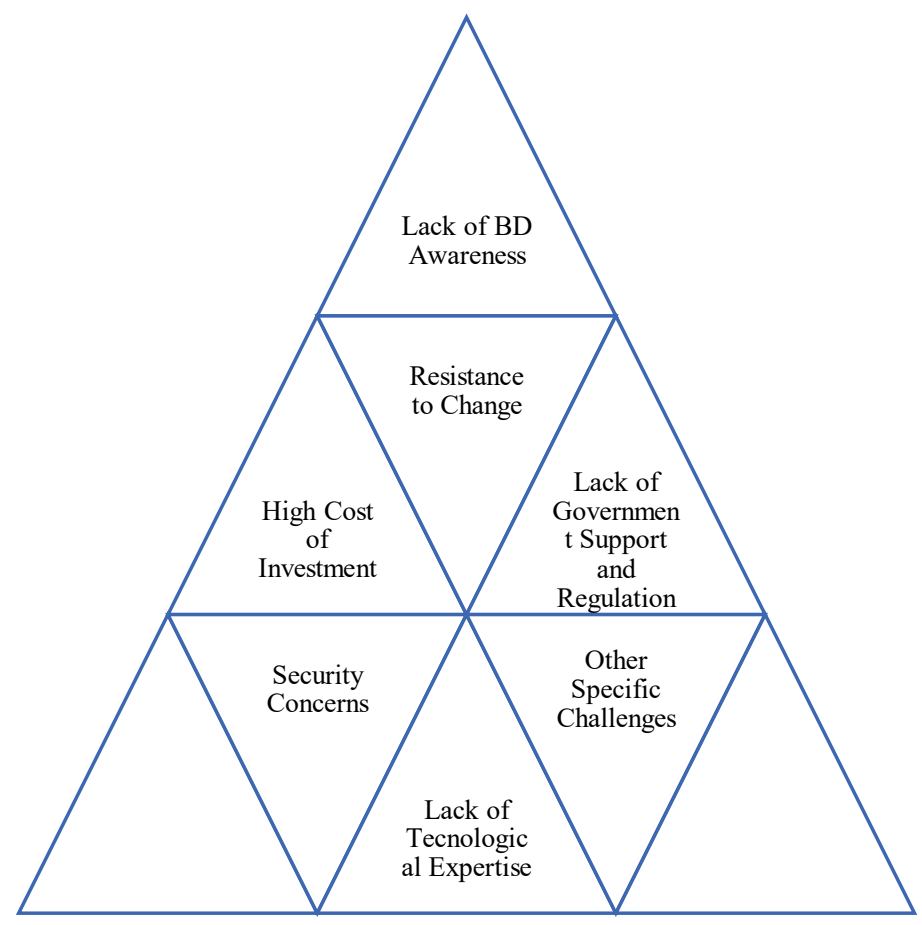

Figure 7: Challenges identifies in the data analysis

\subsection{Lack of Big Data awareness}

Possessing awareness around technologies such as BD implies being able to identify the value this technology can contribute to the business (Silverio-Fernandez et. al., 2019). But as demonstrated in a previous study of this research in which the level of awareness about BD and its characteristics were measured (Reyes Veras et. al., 2021), there is an overall low level of awareness in the construction industry of the Dominican Republic and considering that awareness refers to the knowledge or perception of a fact or situation, in this case BD technology, this detail represents a challenge to overcome in order to achieve an industry-wide adoption of the technology. Participants identified the lack of awareness as an obstacle between the current state and the future adoption of technology at both company and industry level. For instance, some interviewees expressed themselves specifically about the lack of knowledge about the concept of BD and its characteristics: 
"The ignorance on the subject, not knowing the relevance, not knowing that everyone is a Big Data generator $[\ldots]$ I2

"I would say ignorance of the concept and its benefits". I8

"I think the first challenge will be to know about this topic and soak up well about the benefits that can be obtained with the big data implementation". II2

"Well, in terms of big data I would say is that there is not enough information about it, and for the new technology aspect in general is the same that I said before, sometimes we like to wait until there is no doubt that this new thing in which you want to invest works". I14

"I think the main challenge is that is something very new and people now too little or nothing about it, and if you don't know it there is really nothing else you can do". I20

Unawareness of the basic concept of BD technology indicates that for the technology to be adopted by the industry it is necessary to resolve this situation by promoting the popularization of the concept, its benefits, and characteristics. Companies must be proactive in researching technologies that could improve the services they offer, as well as in disseminating knowledge about such technologies.

Likewise, Interviewee I13 also stressed the fact that although the technology may be known in other areas, its impact on the construction industry is unknown:

"Well, I think that the main thing is the lack of knowledge on the topic, I bet that almost anyone haven't heard of the implementation of BD in construction, they may have heard of its implementation in other areas like my case, but I really doubt that you will find many people that know about how this can be used in construction projects. $I 13$

The aforementioned study on the measurement of BD awareness levels and its characteristics (Reyes Veras et. al., 2021), also showed that there is also a low level of knowledge of the technology in other industries, which makes its popularization in construction even more difficult.

The lack of deep understanding about BD, its functions, features, and benefits inhibit a future adoption of the technology, and unlike other challenges that may be addressed in the future, this is a problem that must be solved beforehand since the implementation of the technology depends on it. Nowadays there are many examples of BD applications in other industries that could be replicated in construction, furthermore there are an increasingly number of examples of the impact of this technology within the industry. Still, it is necessary that companies adopt the habit of exploring new techniques and tools which requires a change in mindset and to become technologically driven.

\subsection{High cost of investment}

It has been shown that companies and industries with a marked digital orientation find it easier to incorporate new technologies into their processes (Tabesh, et. al., 2019 and Chen et. al., 2020). There is no doubt that the investment cost of a technology and its requirements greatly influences its implementation. Because of this many sources identified the initial cost of acquiring BD infrastructure and training (TatvaSoft, 2021), the cost of using and maintaining this infrastructure (Bello et. al., 2021), as well as the lack of financial planning of the companies for the implementation of new technologies (Chuah et. al., 2021), as challenges to overcome in the adoption of the BD concept in the construction industry. Moreover, this challenge was identified by many participants during the data collection process as one of their biggest concerns about the adoption of new technologies. Such is the case presented by Interviewees I13 and I20 in the next statements:

"For us the main thing is the relationship cost/return of the investment, we evaluate some other aspects but that is in most cases what prevents us of dabbling in any new technological development". I20 
"[...] but also, the possible costs of implementation, how much you would need to invest to adopt this technology and at this point there is little, or none proven information of its results for the construction [...]". I13

Also, Interviewees I6 and I18 provided some detail into the necessary investment and why the cost may be out of the company's financial capabilities with the following comment:

"[...] Also, investment in hardware and software. By requiring that the information is centred and stored correctly or beneficially for the company, high-speed computers are required for data management and software is required to help and establish the channels and protocols for the data. Both (hardware and software) are very large and short-term investments that companies must contribute". I6

"[...] sometimes it requires a great investment out of the economic capacity of the companies, since, you need to update your hardware, buy software's and train your employees on how to use those programs, usually with and official source that normally are outside the country, so of course, there are many aspects involved, but the economic is key, it could determine whether or not you can make the adoption". 118

Lastly, Interviewee I14 argued about the reality of many companies, which do not have financial planning, or a budget dedicated to new technological investments:

"[...] and finally capital investment required most companies don't have capital dedicated to try new methods, tools, and technologies, they usually make an investment after something is proven to work in a positive way, avoiding that way any risk". II4

The financial capacity of a company largely determines its ability to invest in new technologies, even so, when some technologies are not compatible with the company's current systems and require a high investment to adapt the infrastructure, this factor becomes even more decisive. Which makes the case of the construction industry more disadvantageous, since it has been shown that even large companies have more possibility of investing in the adoption of BD still have basic systems and, in some cases, analogous for carrying out their activities, which would exponentially increase the investment to adapt equipment to the needs of technology. Having said this, it was determined by many authors (TatvaSoft, Bello and Chuah et. al., 2021) and the data analysis process, that there must be a certain affordability of the technology for it to be considered for adoption.

\subsection{Resistance to change}

Construction industry is well known for its traditional practices that produces resistance for companies every time they seek to introduce a new method or adopt a new technology (Fernandez Silverio et. al., 2019). This resistance is an element to overcome when looking to create changes in the way processes are normally carried out. Many participants identified this factor as a challenge for the implementation of technologies such as BD both in their organizations and in the industry. For instance, when asked to describe the challenges faced by the industry and their organizations in the adoption of this type of technology, I3 expressed the following:

"[...] like the ability of the employees to accept it and decide to use it, because independently, sometimes you have an integrated system, where you can find everything, but people keep using other technology they feel more comfortable with [...] The people keep using WhatsApp, people keep using the mail, people keep using another thing. So yes, the resistance to change [...]". I3

This indicates that even when a more efficient way of carrying out a process is adopted within a company, its benefits will not necessarily be fully exploited, since people tend to stick with the methods with which they feel most comfortable ignoring and wasting the opportunities offered by the new system.

Similarly, I5 and I6 also commented the following:

"There is a resistance to implementation because it represents a process and additional work time within the large workload that already exists in a construction project. Likewise, I have had clients prone to make multiple changes at all stages of a construction project that are reluctant to believe in the efficiency of information management because they expect the execution of constant change immediately which is unsustainable". I5 
Also,

"[...] I would say first work culture, since employees at all levels always feel dissatisfaction when trying to change current work methodology [...]”. I6

In this case, the participants also expressed the reason why resistance occurs on many occasions, and this is related to the increase in work incurred by the adoption of technology, since, in many cases, it is expected that the adoption process does not interrupt with the other productive activities of the company.

The previous statements show that either by habit or because the implementation would imply an increase in the work volume, there is a resistance that hinders these processes. It is recommended that to overcome resistance to change it is necessary to overcome opposition by engaging stakeholders those who are against the proposed change; engage effectively with its employees by listening to their feedback; do not introduce everything at once, time and preparation are key, companies should prepare then act and after this, is still necessary to introduce a proper management and support to make sure everything runs accordingly; finally, effective communication about the new things to be introduced will ensure everyone understands their role and what to expect of the change.

\subsection{Lack of government support and regulation}

Governments in many cases are precursors of the implementation of new technologies, such is the case of BIM (NBS, 2020) in the United Kingdom, which drove the adoption of this technology throughout the industry. Furthermore, some may argue about the close relationship between government and technology (Shepheard, 2019) in cases where the technology can provide a solution to needs of the institution. On the other hand, when the government does not recognize or promote the adoption of a technology, an environment of incompatibility is created that can force companies either to double work or to remain in the original format, situation acknowledged by the participants who issued the next comments:

"Sometimes you try to implement something new and at the end you need to use the old methods anyway because they are not compatible with what the government ask and can process ". I7

"I would say the government blockade, somethings you invest in something new but the government doesn't recognises the new format in which you are now working so you end up having to go back to the old ways to be able to submit and get approval to start the project [...] Sometimes they don't even tell you, when you ask about the status sometimes even months after the submission is when you learn that they don't recognise that format'. I21

Added to this situation is the lack of incentive by the government, the participants expressed that since the government institution is one of the main beneficiaries of the construction industry development, it should promote the adoption of technologies that, as mentioned above, align with its needs. With the following statement both interviewees I14 and I19, highlight the government's responsibility for the adoption of new technologies within the industry.

"I think quite a few come to mind but needed to say the most important are lack of incentives from the government, they should be the most interested in the evolution of the industry [...]”. I14

"[...] the lack of incentives from the government, as I said in some countries the government is asking the companies to adopt some technologies, but they have regulations in place to make sure that the companies can actually do it". I19

According to the above, it can be concluded that governments should promote and regulate the use of technologies that are beneficial for the development of industries, which translates into direct benefits for society. Governments should also promote, encourage, regulate and back up the adoption of technologies like BD that contribute to transparency, better decision-making, and overall management of digital information.

\subsection{Lack of technological expertise}

The implementation of a new technology such as BD within a company implies an adjustment process that requires updating not only the equipment but also the knowledge of the human resources within the company, so that the 
latter can take full advantage of the benefits of this new technology. The hiring of trained employees is also complicated since according to Gohil and Akhilesh (2018) "skilled BD analytics workers are hard to find". This need has been identified as a challenge for two main reasons: first the aggregated cost of training the staff to use the technology (which falls within the high cost of investment discussed before) and second, the ability of people to learn to use this technology. It has been demonstrated that many technologically driven companies characterized by having young and technologically active staff, have more ease in the adoption of new technologies (Silverio Fernandez et. al., 2019), so it is easy to assume the opposite case, where in companies that tent to adhere to traditional methods and with more senior staff, it is more difficult for them to adopt new tools and processes. "Maybe training, that the person, I mean, the people that need to access some type of information system
knowing how to do it, will prepare them to do it". I3

Also,

"Well we always need to determine if the adoption, or any change ... that we try to introduce to the company, has to be assessed in terms of time, investment and the capability of the workforce to adapt that change, because we have in the past invested in some software's to make more efficient some process but the investment required to train the employees in its use is too high, and we end up with a software that only two or three people know how to use, which offers little advantage to the company as a whole". I16

This opinion expressed by the participants in the previous comments is mostly reflected in environments where company staff is not constantly trained in order to keep up to date, the challenges for the adoption of new technologies increases since it is easier to learn new technological developments little by little and overtime than to make a great leap from an old system to a modern one without knowing the developments that have been made in between. Therefore, it is necessary for companies to maintain a good training program in charge of exploring and implementing the small developments that are being generated in the industry, which in turn would facilitate the ability of the staff to grasp the new technologies that like BD require a more technical level.

\subsection{Security concerns}

There are many concerns that surround data management technologies such as BD, since some sources assure that there are no protocols to ensure the analysed data does not contain private or sensitive information about the users who generate it (Small, 2019), plus the considerations that the data is not protected or trustworthy (Brandín and Abrishami, 2021). This apprehension is identified as a challenge for both the primary and secondary data as long as the procedures that ensure the rights of the people and companies that generate personal and commercial data are not violated cannot be identified (Bello et. al., 2021). In this regard, interviewee I21 stated the following:

"[...] it raises some questions about security and the management of the data that we allow some apps and companies to have about us [...] of course, until you can assure that this technology won't present any risk to companies and their private information, I don't see it really been used broadly or implemented in construction”. I21

The identification of the security threat posed by the technology comes in the hand with a deep understanding of its operation, still, some clarification is needed on how the analysed data is handled by the BD tools and with this plus the assurance of the proper use of this data, solutions that could be provided by the awareness and popularization of $\mathrm{BD}$ processes.

\subsection{Other implementation issues}

The lack of motivation from stakeholders for the adoption of new technologies such as BD, also that it takes a long time to implement technologies like this and on top of that there is little to none support or motivation from the industry together with the fact that companies don't usually have a funds for the adoption of new technologies and the tradition that companies only adopt changes that produce proven positive changes are among the concerns raised by participants when asked about challenges for BD implementation. In this last topic interviewee I10 expressed the following:

"There is no evidence of positive results of implementation in the construction industry that I am aware of". $I 10$ 
The previous comment shows the need to provide examples showing benefits of the implementation of new technologies, in the case of $\mathrm{BD}$ as well as many other technologies, these examples exist but are not yet popular, so the real challenge lies in publicizing the success stories in order to promote industry-wide implementation.

When the challenges identified by the participants are analysed, it can be observed that only two of them (the high investment cost and the security concerns) correspond with those identified in the literature. This is largely due to the low level of knowledge that is possessed in the construction industry of the Dominican Republic about BD and its characteristics (Reyes Veras et. al., 2021). Likewise, the need to promote technology and educate on its concept and operation is generated. Understanding factors such as governance, latency and dark data require experience that is only achieved through education and the use of technology. So, the primary focus should be to make it popular by demonstrating the benefits of BD and the return over investment. This would encourage the BD adoption in organisations and the industry as whole.

The use of thematic analysis to examine the collected data allowed the identification of main challenges to be overcome in the adoption of the BD concept in the construction industry. Through this methodology it was possible to deeply explore the opinion of the participants identifying the ideas and patterns which resulted in the themes presented before (Caufield, 2019), six main implementation defying elements and other areas of concern, which will allow organizations to plan ahead and make the necessary preparations whenever they wish to incorporate technologies such as BD into their organizations.

\section{CONCLUSION}

The construction industry is at a turning point. The current requirements of both users and the environment forces construction industry to evolve by adopting tools and technologies that allow it to keep up with today's society needs. At the same time, BD has been identified as an emerging technology that could help the industry meet these needs, its ability to improve aspects such as decision-making, resource management, transparency and communication is what has made more and more companies use this tool to provide their services.

The exploration of the element that enable the adoption of BD in the construction industry seeks to facilitate and accelerate the implementation process by providing insightful knowledge that will help companies make better decisions when evaluating the feasibility of technology. In the specific case of the challenges identified in this study, these will serve to help companies better plan their technology adoption process, mainly considering aspects such as the need to tackle the lack of awareness by disseminating and promoting the concept of BD which will not only generate a better understanding of technology by making sure that present and future professionals understand the technology and its benefits, but will also guarantee an implementation process with less resistance. Moreover, popularizing the technology also ensures that it becomes more affordable and the costs for its implementation are reduced. Companies will also be able to provide well based information to its employees and establish mechanisms that will allow them to overcome resistance to change, as well as having the basis to demand from government and industry officials the necessary support to achieve the common objectives. The understanding of these challenges will also serve as a possible source of information which would reduce the technology gap as well as the general ignorance of technology also motivating further research from the industry stakeholders.

Both of the main elements identified in this study such as lack of awareness, high cost of investments, resistance to change, lack of government support and regulation, lack of technological expertise from workers and security concerns as well as the elements of less impact such as lack of motivation from stakeholders, long time of implementation, lack of industry support, lack financial vision from the companies and attachment to traditions, are elements that influence the adoption of technologies such as BD, and their understanding will serve for both companies and the construction industry to prepare an implementation plan attached to reality where the necessary tools are presented for a successful implementation of the technology.

This study is limited to exploring and identifying the challenges faced by the adoption of new technologies such as Big Data in both organizations and the industry, and its results apply within the structure of the construction industry of the Dominican Republic, but with the possibility that it can be used as base for BD implementation in the industries of other countries with similar characteristics.

Finally, this study will serve as a source of knowledge for construction workers and decision-makers that seek to incorporate new technologies such as BD in their organizations, as well as in digital-driven professionals. Also, for the preparation of present and future construction experts serving as an educational tool that contributes to 
obtaining the level of knowledge necessary for an adoption of technology at the industry level. In the same way, it will contribute to the general research that explores other elements of the implementation of BD in the construction industry and which its main output is to develop a framework that can guide industry stakeholders in a successful adoption of the technology.

\section{ACKNOWLEDGEMENTS}

This research received funding from the Ministry of Higher Education, Science and Technology (MESCyT), Santo Domingo, Dominican Republic. The authors would like to give their sincere thanks and appreciation to the interviewees that accepted to participate in the study.

\section{REFERENCES}

Abusalah, M., 2021. Innovation Management in Construction — Practical Approach. Agile Insider.

Boyd, D. and Crawford, K., 2012. Critical questions for big data: Provocations for a cultural, technological, and scholarly phenomenon. Information, communication \& society, 15(5), pp. 662-679.

Aversa, J., Hernandez, T. and Doherty, S., 2021. Incorporating big data within retail organizations: A case study approach. Journal of Retailing and Consumer Services, 60, pp. 102447.

Bag, S., Pretorius, J.H.C., Gupta, S. and Dwivedi, Y.K., 2021. Role of institutional pressures and resources in the adoption of big data analytics powered artificial intelligence, sustainable manufacturing practices and circular economy capabilities. Technological Forecasting and Social Change, 163, pp. 120420.

Baig, M.I., Shuib, L. and Yadegaridehkordi, E., 2019. Big data adoption: State of the art and research challenges. Information Processing \& Management, 56(6), pp. 102095.

Balti, H., Ben Abbes, A., Mellouli, N., Farah, I.R., Sang, Y. and Lamolle, M., (2020). A review of drought monitoring with big data: Issues, methods, challenges and research directions. Ecological Informatics, 60, pp. 101-136.

Bell, D., Lycett, M., Marshan, A. and Monaghan, A., (2021). Exploring future challenges for big data in the humanitarian domain. Journal of Business Research, 131, pp. 453-468.

Bello, S.A., Oyedele, L.O., Akinade, O.O., Bilal, M., Davila Delgado, J.M., Akanbi, L.A., Ajayi, A.O. and Owolabi, H.A., (2021). Cloud computing in construction industry: Use cases, benefits and challenges. Automation in Construction, 122, pp. 103--441.

Brandín, R. and Abrishami, S., 2021. Information traceability platforms for asset data lifecycle: blockchain-based technologies. Smart and Sustainable Built Environment, Vol. ahead- of-print No. ahead-of-print. https://doi.org/10.1108/SASBE-03-2021-0042.

Braun, V., Clarke, V., Hayfield, N. and Terry, G., (2019). Thematic analysis | a reflexive approach. Available: https://www.psych.auckland.ac.nz/en/about/thematic-analysis.html\#top

Busetto, L., Wick, W. and Gumbinger, C., (2020). How to use and assess qualitative research methods. Neurological Research and Practice, 2(1), pp. 14.

Caesarius, L.M. and Hohenthal, J., 2018. Searching for big data: How incumbents explore a possible adoption of big data technologies. Scandinavian Journal of Management, 34(2), pp. 129-140.

Caulfield, J., (2019), How to do thematic analysis. 6 of September, (accessed October 2021). Available at: www.scribbr.com/methodology/thematic-analysis/

Chalhoub, J., Ayer, S.K. and Ariaratnam, S.T., 2021. Augmented reality for enabling un- and under-trained individuals to complete specialty construction tasks. Journal of Information Technology in Construction, 26, pp. 128-143. DOI: 10.36680/j.itcon.2021.008

Chen, P., Linc, C. and Wud, W., (2020). Big Data Management in healthcare: Adoption challenges and implications. International Journal of Information Management, 26(1), pp. 1-2.

Chang, V., Xu, Y.K., Zhang, J. and Xu, Q., 2021. Research on intelligent manufacturing development approach for China's local valve industry. Smart and Sustainable Built Environment, 10(2), pp. 293-321. DOI 10.1108/SASBE-03-2021-0044 
Chuah, M.H. and Thurusamry, R., (2021). Challenges of big data adoption in Malaysia SMEs based on Lessig's modalities: A systematic review. null, 8(1), pp. 1968191.

Cohen, B. and Crabtree, D., (2006), Semi-structured Interviews. Available: http://www.qualres.org/HomeSemi3629.html.

Construction Leadership Council (CLC), (2018). Smart Construction - a guide for housing clients. Available: https://www.constructionleadershipcouncil.co.uk/wp-content/uploads/2018/10/181010-CLC-SmartConstruction-Guide.pdf

Creswell, J.W., (2013). Research Design: Qualitative, Quantitative, and Mixed Methods Approaches. Thousand Oaks, CA.: Sage publications.

Creswell, J.W. and Creswell, J.D., (2017). The Selection of a Research Approach. Research Design Qualitative, Quantitative, and Mixed Methods Approaches. Michigan, USA: Sage Publishing, pp. 3-22.

Crouch, M. and Mckenzie, H., (2006). The logic of small samples in interview-based qualitative research. Social Science Information, 45(4), pp. 483-499.

Dejonckheere, M. and Vaughn, L.M., (2019). Semistructured interviewing in primary care research: a balance of relationship and rigour. Family Medicine and Community Health, 7(2), pp. e000057.

Gohil, H. and Ayer, A., (2018) Insurance fraud detection and prevention in the era of big data curbing fraud by application of advanced analytics across policy lifecycle, WNS.

Hitchings, R. and Latham, A., (2020). Qualitative methods I: On current conventions in interview research. Progress in Human Geography, 44(2), pp. 389-398.

Jahanger, Q. K., Louis, J., Pestana, C. and Trejo, D., 2021. Potential positive impacts of digitalization of construction-phase information management for project owners. Journal of Information Technology in Construction, 26 (ISSN 1874-4753), pp. 1-22. DOI:10.36680/j.itcon.2021.001.

Johansen, K.W., Nielsen, R., Schultz, C. and Teizer, J., 2021. Automated activity and progress analysis based on non-monotonic reasoning of construction operations. Smart and Sustainable Built Environment, Vol. ahead-of-print No. ahead-of- print.

Khurshid, M.M., Zakaria, N.H., Rashid, A., Kazmi, R., Shafique, M.N. and Ahmad, M.N., 2019. Analyzing diffusion patterns of big open data as policy innovation in public sector. Computers and Electrical Engineering, 78, pp. 148-161.

Knowles, E.E.M., 2020. Strengths and Limitations of Harnessing Big Data to Understand the Genetics of Adoption and Mental Health. Biological psychiatry; Brain Circuits and the Emergence of Schizophrenia, 87(8), pp. e21-e22.

Kumar, R., (2014). Research methodology: a step by step guide for beginners. Nurse researcher, 19(4), pp. 45.

Leonard-Barton, D. and Kraws, W.A., (1985). Implementing New Technology. Harvard Business Review. Available: https://hbr.org/1985/11/implementing-new-technology.

Lu, W., 2019. Big data analytics to identify illegal construction waste dumping: A Hong Kong study. Resources, conservation and recycling, 141, pp. 264-272.

Lu, W., Lee, W.M.W., Xue, F. and Xu, J., 2021. Revisiting the effects of prefabrication on construction waste minimization: A quantitative study using bigger data. Resources, conservation and recycling, 170, pp. 105579.

Maroufkhani, P., Tseng, M., Iranmanesh, M., Ismail, W.K.W. and Khalid, H., (2020). Big data analytics adoption: Determinants and performances among small to medium-sized enterprises. International journal of information management, 54, pp. 102-190.

Martinez, G., Renukappa, S. and Suresh, S., (2021) Business model innovation in small enterprises from developing countries during COVID-19 outbreak: exploring drivers and BMI outcomes. Int. J. Business Environment.

McCombes, S., (2021). Sampling Methods | Types and Techniques Explained. Available: https://www.scribbr.com/methodology/sampling-methods/ 
McNiff, K., (2016). What is Qualitative Research? QSR International. Available: https://www.qsrinternational.com/nvivo-qualitative-data-analysis-software/resources/blog/what-isqualitative-research

Miloslavskaya, N. and Tolstoy, A., (2016). Big Data, Fast Data and Data Lake Concepts. Procedia Computer Science, 88, pp. 300-305.

Mourtzis, D., Vlachou, E. and Milas, N., 2016. Industrial Big Data as a Result of IoT Adoption in Manufacturing. Procedia CIRP; 5th CIRP Global Web Conference - Research and Innovation for Future Production (CIRPe 2016), 55, pp. 290-295.

Naoui, M.A., Lejdel, B., Ayad, M., Amamra, A. and Kazar, O., 2021. Using a distributed deep learning algorithm for analyzing big data in smart cities. Smart and Sustainable Built Environment, 10(1), pp. 90-105.

NBS, (2020). 10th National BIM Report. London, UK: NBS Enterprises Ltd. Available: https://www.thenbs.com/knowledge/national-bim-report-2020

Nik-Bakht, M., Lee, J. and Dehkordi, S.H., 2021. Bim-based reverberation time analysis. Journal of Information Technology in Construction, 26(ISSN 1874-4753), pp. 28-38. DOI: 10.36680/j.itcon.2021.003

Ngo, J., Hwang, B. and Zhang, C., (2020). Factor-based big data and predictive analytics capability assessment tool for the construction industry.

Oudjehane, A. and Moeini, S., (2017). Big data in construction projects: Risk and opportunity management.

Paycor, (2019) Overcoming Employee Resistance to Change in the Workplace. Available: https://www.paycor.com/resource-center/articles/overcoming-employee-resistance-to-changein-the-workplace/.

Raguseo, E., 2018. Big data technologies: An empirical investigation on their adoption, benefits and risks for companies. International Journal of Information Management, 38(1), pp. 187-195.

Reyes Veras, P., Renukappa, S. and Suresh, S., (2021). Awareness of Big Data concept in the Dominican Republic construction industry: an empirical study. DOI 10.1108/CI-05-2021-0090.

Salleh, K.A. and Janczewski, L., 2019. Security Considerations in Big Data Solutions Adoption: Lessons from a Case Study on a Banking Institution. Procedia Computer Science; CENTERIS 2019 - International Conference on ENTERprise Information Systems / ProjMAN 2019 - International Conference on Project Management / HCist 2019 - International Conference on Health and Social Care Information Systems and Technologies, CENTERIS/ProjMAN/HCist 2019, 164, pp. 168-176.

Sayah, Z., Kazar, O., Lejdel, B., Laouid, A. and Ghenabzia, A., 2021. An intelligent system for energy management in smart cities based on big data and ontology. Smart and Sustainable Built Environment, 10(2), pp. 169-192.

S. Shah, C. B. Soriano and A. D. Coutroubis, (2017). Is big data for everyone? the challenges of big data adoption in SMEs, - 2017 IEEE International Conference on Industrial Engineering and Engineering Management (IEEM) 2017, pp. 803-807.

Shepheard, M., (2019) Future technology in government. Available: https://www.instituteforgovernment.org.uk/explainers/future-technology-government.

Silva, J., Hernandez, L., Crissien, T., Pineda Lezama, O.B. and Romero, J., 2019. Big Data Aplication for Selecting Theses Topics. Procedia Computer Science; The 10th International Conference on Emerging Ubiquitous Systems and Pervasive Networks (EUSPN-2019) / The 9th International Conference on Current and Future Trends of Information and Communication Technologies in Healthcare (ICTH-2019) / Affiliated Workshops, 160, pp. 538-542.

Silverio Rodriguez, A.K., (2020). Implementation of building information modelling in the Dominican Republic construction industry, University of Wolverhampton.

Silverio-Fernandez, M., Renukappa, S. and Suresh, S., (2019). Evaluating critical success factors for implementing smart devices in the construction industry: An empirical study in the Dominican Republic. Engineering, Construction and Architectural Management, 26(8), pp. 1625-1640. 
Small, M., (2019). Big Data Analytics - Security and Compliance Challenges. Kuppingercole.

Tabesh, P., Mousavidin, E. and Hasani, S., (2019). Implementing big data strategies: A managerial perspective. Business Horizons, 62(3), pp. 347-358.

Tatvasoft, (2021), top big data adoption challenges faced by cxos.

Tamiminia, H., Salehi, B., Mahdianpari, M., Quackenbush, L., Adeli, S. and Brisco, B., 2020. Google Earth Engine for geo-big data applications: A meta-analysis and systematic review. ISPRS Journal of Photogrammetry and Remote Sensing, 164, pp. 152-170.

The World Bank, (2021). República Dominicana: panorama general. Santo Domingo. Available at: www.worldbank. org/en/country/dominicanrepublic/overview\#1.

Valdez Albizu, H., (2021). Resultados preliminares de la economía dominicana enero-marzo 2021. Santo Domingo, D. N., Republica Dominicana: Banco Central de la Republica Dominicana.

Vellante, B., (2021). 7 Ways Construction Contractors Can Leverage the Power of Big Data. Construction Innovation.

Willar, D., Waney, E.V.Y., Pangemanan, D.D.G. and Mait, R.E.G., 2021. Sustainable construction practices in the execution of infrastructure projects. Smart and Sustainable Built Environment, 10(1), pp. 106-124.

Wu, J., Li, H., Liu, L. and Zheng, H., 2017. Adoption of big data and analytics in mobile healthcare market: An economic perspective. Electronic Commerce Research and Applications, 22, pp. 24-41.

Xu, J., Lu, W., Ye, M., Xue, F., Zhang, X. and Lee, B.F.P., 2020. Is the private sector more efficient? Big data analytics of construction waste management sectoral efficiency. Resources, conservation and recycling, 155, pp. 104674. 